\title{
PELATIHAN KONSELING INFORMASI DAN EDUKASI UNTUK SISWA SMK MUHAMMADIYAH DORO KABUPATEN PEKALONGAN MENGENAI PENGGUNAAN OBAT DENGAN TANYA LIMA “O”
}

\author{
Sitti Rahmatullah, Yulian Wahyu Permadi \\ Universitas Muhammadiyah Pekajangan Pekalongan \\ Jl.Raya Ambokembang No 8 Kedungwuni Pekalongan \\ e-mail: amma88.an@gmail.com
}

\begin{abstract}
ABSTRAK
Masyarakat Indonesia saat ini sudah mulai terbiasa dengan penggunaan berbagai jenis obat-obatan dengan tujuan menyembuhkan penyakit, mengontrol, ataupun sebagai suplemen untuk menunjang aktifitas sehari-hari. Tujuan pengabdian masyarakat ini untuk memperkenalkan kepada siswa SMK Muhammadiyah Doro mengenai materi "Cerdas Gunakan Obat dengan Tanya Lima O". Metode pelaksanaan pengabdian masyarakat ini adalah terlebih dahulu pengumpulan data siswa SMK Muhammadiyah Doro, selanjutnya dilakukan pretes pada hari pelaksanaan, penyuluhan menggunakan metode ceramah dan konseling informasi dan edukasi. Hasil dari kegiatan ini adalah meningkatnya pengetahuan siswa SMK Muhammadiyah Doro tentang penggunaan obat dengan tanya lima "O" sebesar $86 \%$ dari nilai yang baik, nilai cukup menurun $14 \%$ dari sebelum dilakukan kegiatan ceramah, untuk nilai kurang menjadi $0 \%$ artinya setelah dilakukan kegiatanini jumlah siswa semua sudah mempunyai pengetahuan yang meningkat.Diharapkan kegiatan ini dapat meningkatkan pengetahuan siswa SMK Muhammadiyah Doro mengenai cara penggunaan obat dengan tanya lima "O", sehingga siswa bisa lebih terjamin dalam mengkonsumsi obat.
\end{abstract}

Kata kunci: konseling, edukasi, informasi, obat, siswa

\begin{abstract}
Indonesian people are now getting used to using various types of drugs with the aim of curing diseases, controlling, or as a supplement to support their daily activities. The purpose of community service is to introduce to students of Muhammadiyah Doro Vocational School about the material "Smart Use of Medicines by Asking Five O". The method of implementing community service is firstly collecting data on students of Muhammadiyah Doro Vocational School, then pretesting on the day of implementation, counseling using the lecture and counseling methods. The result of this activity is an increase in the knowledge of SMK Muhammadiyah Doro students about the use of drugs by asking five "O's" by $86 \%$ of the good grades, the value is sufficiently decreased by $14 \%$ from before the lecture activities are carried out, for a value of less than $0 \%$ meaning after this activity is carried out all students already have increased knowledge. Hopefully this activity can increase the knowledge of students of SMK
\end{abstract}


Muhammadiyah Doro on how to use drugs by asking five "O's", so students can be more secure in consuming drugs.

Keywords: counseling, education,information, drugs students, 


\section{PENDAHULUAN}

Penyuluhan kesehatan merupakan suatu kegiatan sosial yang dilakukan oleh semua tenaga kesehatan untuk menyebarkan informasi tentang kesehatan yang didapatkan kepada masyarakat awam sehingga masyarakat mendapatkan edukasi dan mengetahui informasi kesehatan yang disampaikan.

Masyarakat Indonesia saat ini sudah mulai terbiasa dengan penggunaan berbagai jenis obat-obatan dengan tujuan menyembuhkan penyakit, mengontrol, ataupun sebagai suplemen untuk menunjang aktifitas sehari-hari. Hal ini dapat disebabkan oleh berbagai faktor seperti perkembangan penyakit, produksi berbagai jenis obat-obatan dan suplemen serta mulai diberlakukannya jaminan kesehatan nasional yang memungkinkan masyarakat mendapatkan akses yang lebih mudah untuk mendapatkan pengobatan. Perkembangan tersebut menimbulkan berbagai dampak positif maupun negatif. Dampak positif yang dapat terlihat adalah semakin banyaknya masyarakat yang mulai peduli terhadap kesehatan dengan memeriksakan diri ke tempat-tempat pelayanan kesehatan. Sedangkan dampak negatif yang mungkin timbul dengan meningkatnya penggunaan obat di masyarakat adalah kesalahan dalam menggunakan obat. Hal ini dapat terjadi karena kurangnya pengetahuan dan informasi yang disampaikan kepada masyarakat terkait penggunaan obat yang baik dan benar. Kesalahan dalam penggunaan obat dapat menyebabkan kerugian baik bagi masyarakat maupun bagi lingkungan.

Ikatan Apoteker Indonesia (IAI) sebagai salah satu organisasi profesi kesehatan saat ini mulai mencanangkan kegiatan penyuluhan kepada masyarakat terkait penggunaan obat yang baik dan benar. Kegiatan penyuluhan ini mempuyai tema "Cerdas menggunakan obat dengan tanya 5 O" apoteker sebagai profesi kesehatan yang concern terhadap pemakaian obat-obatan di masyarakat dihimbau untuk terus melakukan penyuluhan tersebut di manapun agar masyarakat paham mengenai 
penggunaan obat yang benar sehingga tujuan pengobatan dapat tercapai serta tidak menimbulkan kesalahan dalam penggunaan obat [1]

Menurut penelitian masa kini, obat-obatan tradisional memang bermanfaat bagi kesehatan dan kini digencarkan penggunaannya karena lebih mudah dijangkau masyarakat, baik harga maupun ketersediaannya. Saat ini, obat tradisional banyak digunakan karena menurut beberapa penelitian tidak menyebabkan atau minim efek samping dan masih bisa dicerna oleh tubuh. Karena itu, banyak perusahaan yang mengolah obatobatan tradisional yang telah dimodifikasi. Obat-obat tradisional yang banyak dijual di pasar biasanya berbentuk kapsul, serbuk, cair, simplisia dan tablet [2]

Hasil yang diharapkan dari kegiatan ini adalah meningkatkan pengetahuan siswa SMK Muhammadiyah Doro mengenai cara penggunaan obat dengan tanya lima "O", sehingga siswa bisa lebih terjamin dalam mengkonsumsi obat.

\section{METODE PELAKSANAAN}

Metode yang digunakan untuk mencapai tujuan dalam kegiatan ini yaitu:

1. Mengundang siswa SMK Muhammadiyah Doro

Semua siswa SMK Muhammadiyah Doro untuk mengikuti pelatihan konseling informasi dan edukasi pada hari dan tanggal yang telah ditentukan.

2. Pretest

Sebagai tahap awal dilakukan pretes untuk semua siswa SMK Muhammadiyah bertujuan untuk mengetahui tingkat pengetahuan siswa dalam penggunaan obat. Pretes memuat apakah nama dan kandungan obat, khasiat, dosis, cara penggunaan, dan efek samping obat.

3. Penyuluhan

Siswa SMK Muhammadiyah Doro diberikan penyuluhan bertujuan untuk meningkatkan pengetahuan mengenai penggunaan obat dengan 
tanya lima "O" tentang nama dan kandungan obat, khasiat, dosis, cara penggunaan, dan efek samping obat. Hasil dari penyuluhan diharapkan kepada seluruh Siswa SMK Muhammadiyah Doro lebih memahami cara pemilihan dan penggunaan obat yang benar, sehingga mengurangi angka kesalahan penggunaan obat.

4. Praktek konseling informasi dan edukasi

Praktek konseling informasi dan edukasi dilakukan untuk memberikan informasi kepada siswa SMK Muhammadiyah Doro cara berkomunikasi dengan baik sesuai aturan yang benar. Praktek dipandu oleh beberapa pemandu yang berkompeten di bidangnya.

5. Melakukan Evaluasi

Evaluasi kegiatan ini dilakukan kepada siswa SMK Muhammadiyah Doro yang menjadi peserta. Kemampuan Peserta yaitu siswa SMK Muhammadiyah Doro dinilai melalui evaluasi (postes) yang dilakukan kepada 30 peserta.

\section{HASIL DAN PEMBAHASAN}

Pada pengabdian masyarakat yang dilakukan kali ini bertujuan untuk memperkenalkan kepada siswa SMK Muhammadiyah Doro mengenai materi "Cerdas Gunakan Obat dengan Tanya Lima O". Hal-hal yang dilakukan berupa memceramahkan materi tersebut kepada siswa dan memberikan contoh sediaan kepada siswa. Materi cerdas gunakan dengan tanya lima $O$ yang pertama, obat ini apa nama dan kandungannya, Dimana dimaksudkan agar konsumen mengetahui dan mengenali obat apa yang akan dibeli. Kedua, Obat ini apa khasiatnya, suatu obat memiliki khasiat atau indikasi yang dicapai sehingga pasien diharapkan memahami indikasi atau khasiat obat yang dikonsumsi. Ketiga, obat ini berapa dosisnya, dosis berpengaruh kepada efek yang akan dihasilkan oleh suatu obat di dalam tubuh, oleh karena itu pasien mengetahui dosis obat yang tepat. Keempat, Obat ini bagaimana cara menggunakannya, Ada berbagai bentuk sediaan obat yang berbeda. Hal 
tersebut bertujuan untuk menyesuaikan sasaran terapi sehingga efek pengobatan yang diharapkan tercapai sesuai tujuan. Kelima, Obat ini apa efek sampingnya, beberapa obat memiliki efek samping. Ada efek samping yang dapat ditolerir seperti mengantuk atau mengiritasi lambung. Namun ada juga efek samping yang berbahaya seperti gangguan fungsi hati dan ginjal [1]

Siswa SMK Muhammadiyah Doro hendaknya waspada terhadap efek samping tersebut dan segera konsultasi ke dokter atau menghentikan penggunaan obat apabila efek samping terasa mulai mengganggu. Selain melakukan ceramah materi, dan konseling informasi dan edukasi kami juga melakukan sesi tanya jawab kepada peserta dengan memberikan kesempatan kepada peserta untuk menanyakan materi yang telah diberikan. Selanjutnya, dilakukan sesi konseling, informasi, dan edukasi. Sesi Informasi dan Edukasi kepada siswa tersebut dilakukan dengan membagi peserta menjadi beberapa kelompok, dimana KIE yang diberikan terkait dengan materi yang sudah dijelaskan dan pengetahuan umum mengenai obat [3].

Hasil yang dicapai dalam kegiatan pengabdian masyarakat ini yaitu bertambahnya pengetahuan siswa SMK Muhammadiyah Doro diwujudkan dengan hasil evaluasi yang lebih baik sehingga dikatakan pengetahuan meningkat. Selain itu cara pemilihan obat menjadi lebih baik, cara konseling informasi dan edukasi yang meningkat lebih baik.Hasil dari evaluasi terdapat pada tabel 1 .

Tabel 1. Distribusi frekuensi pengetahuan siswa SMK Muhammadiyah Doro sebelum dan sesudah dilakukan ceramah materi

\begin{tabular}{lccc}
\hline Pengetahuan & Sebelum ceramah & $\begin{array}{c}\text { Sesudah } \\
\text { ceramah }\end{array}$ & Keterangan \\
\hline Baik & 3 & 26 & Meningkat $86 \%$ \\
\hline Cukup & 10 & 4 & Menurun $14 \%$ \\
\hline Kurang & 17 & 0 & Tidak Ada \\
\hline Jumlah & $\mathbf{3 0}$ & $\mathbf{3 0}$ & $\mathbf{1 0 0 \%}$ \\
\hline
\end{tabular}

Hasil pengukuran menunjukkan terdapat peningkatan jumlah siswa SMK Muhammadiyah Doro yang memiliki pengetahuan baik setelah 
diberikan pengetahun dengan metode penyuluhan dan praktek konseling informasi dan edukasi tentang pengetahuan mengenai penggunaan obat dengan tanya lima "O" meliputi nama dan kandungan obat, khasiat, dosis, cara penggunaan, dan efek samping sebanyak $86 \%$. Hal ini menunjukkan bahwa metode penyuluhan dan praktek konseling informasi dan edukasi efektif digunakan untuk meningkatkan pengetahuan tentang penggunaan obat karena materi dan metode sangat mudah dipahami sehingga tidak perlu metode yang kompleks untuk menyampaikan materi ini kepada seluruh siswa SMK Muhammadiyah Doro. Metode yang digunakan menggunakan 2 (dua) macam dikarenakan tingkat pendidikan siswa SMK Muhammadiyah Doro bukan dari jurusan kesehatan melainkan jurusan teknik perbaikan bodi otomotif dan multimedia. Pendapat ini sesuai dengan hasil penelitian lubis yang menyatakan bahwa ada pengaruh penyuluhan dengan metode ceramah terhadap peningkatan pengetahuan dan sikap peserta.

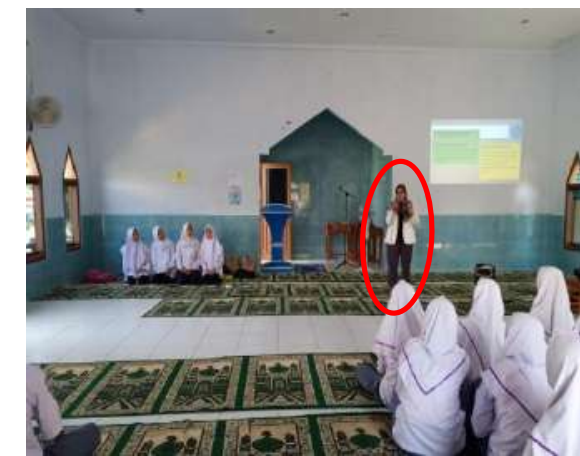

Gambar 1. Kegiatan Ceramah

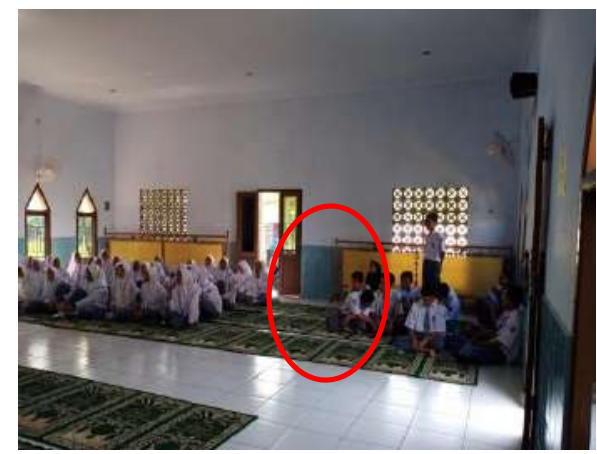

Gambar 3. Kegiatan Praktek Konseling informasi dan edukasi Putra

Gambar 4. Foto Bersama SMK Muhammadiyah Doro

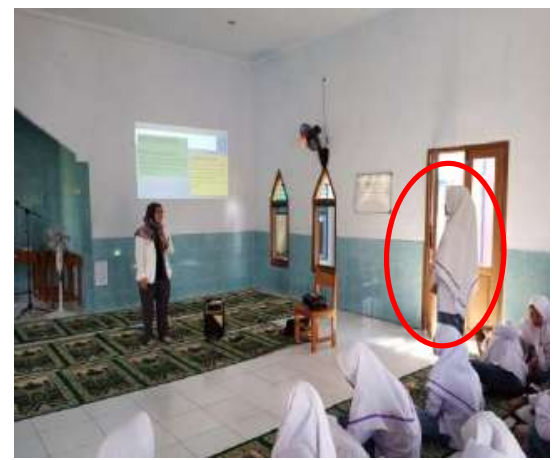

Gambar 2. Kegiatan Praktek KIE Putri Putri

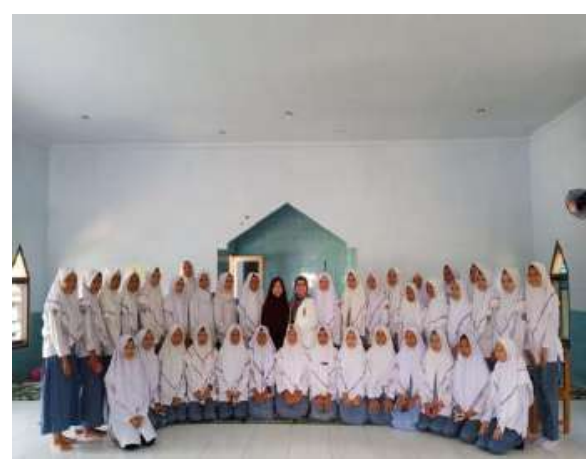


Kegiatan pengabdian masyarakat ini berhasil meningkatkan kemampuan pengetahuan dan ketrampilan konseling informasi dan edukasi siswa SMK Muhammadiyah Doro tentang penggunaan obat dengan tanya lima "O". Dengan bekal pengetahuan dan tambahan ketrampilan diharapkan terbentuk pola penggunaan obat meliputi nama dan kandungan obat, khasiat, dosis, cara penggunaan, dan efek samping obat. Implikasinya siswa SMK Muhammadiyah Doro pada saat konseling informasi dan edukasi mengenai obat mempunyai komunikasi yang baik. Hal ini salah satu tujuan akhir agar tercapai yaitu meningkatnya tingkat kesehatan masyarakat.

\section{SIMPULAN DAN SARAN}

\section{Simpulan}

Simpulan dari kegiatan pengabdian masyarakat ini adalah sebagai berikut:

1. Terbentuknya kelompok konseling informasi dan edukasi yang sudah terlatih

2. Terdapat peningkatan pengetahuan siswa yang memiliki pengetahuan dan keterampilan konseling informasi dan edukasi sesuai dengan aturan yang baik dan benar dilihat dari nilai postest yang terjadi peningkatan yang sangat signifikan.

\section{Saran}

Kegiatan pengabdian masyarakat ini diharapkan dapat berlangsung secara berkesinambungan sehingga dapat tercapai tujuan akhir yaitu meningkatnya tingkat kesehatan bagi masyarakat.

\section{UCAPAN TERIMAKASIH}

Terimakasih kepada Lembaga Penelitian dan Pengabdian Masyarakat Universitas Muhammadiyah Pekajangan Pekalongan yang telah membantu pendanaan kegiatan ini 


\section{DAFTAR PUSTAKA}

1. Depkes RI, 1990, Daftar Obat Esensial Nasional, Departement Kesehatan Republik Indoensia, Jakarta.

2. Anief, 1996, Penggolongan Obat: berdasarkan khasiat dan penggunaan, 9-10, Gadjah Mada University Press, Yogyakarta.

3. Depkes RI, 2004,Keputusan Menteri Kesehatan Nomor 1027/Menkes/SK/IX/2004 Tentang Standar Pelayanan Kefarmasian di Apotek, Departemen Kesehatan Republik Indonesia, Jakarta 